\section{EUS for unexplained mediastinal lesions}

T. J. Savides ${ }^{1}$, C. M. Behling ${ }^{2}$

${ }^{1}$ Professor of Clinical Medicine, University of California, San Diego

${ }^{2}$ Associate Professor of Clinical Pathology, University of California, San Diego

\section{Introduction}

Trans-esophageal endoscopic ultrasound (EUS) with fine needle aspiration (FNA) offers a unique ability to assess and biopsy posterior mediastinal lesions. This review will focus on EUS diagnosis of unexplained posterior mediastinal, lymph nodes, masses, and cysts. Table 1 shows the types of posterior mediastinal lesions which can be diagnosed with trans-esophageal EUS/FNA cytology.

\section{EUS evaluation of enlarged posterior mediastinal lymph nodes}

EUS appearance of normal benign posterior mediastinal lymph nodes

Benign mediastinal lymph nodes are commonly encountered during EUS for non-thoracic indications. These often have a triangular or crescent shape. An echogenic center may be visualized, representing the hilum of the lymph node.

\section{EUS appearance of malignant posterior mediastinal lymph nodes}

EUS findings associated with malignancy include round shape, short-axis diameter greater than 5-10 mm, hypoechoic echotexture, and well-demarcated borders [1,2]. If all 4 features are pres-

Table 1 Posterior mediastinal lesions that can be diagnosed with EUS/ FNA

\begin{tabular}{|l|}
\hline Primary pulmonary cancer \\
Non-small cell lung cancer \\
Small Cell Lung Cancer \\
\hline Metastatic cancer from extra-thoracic malignancy \\
\hline Lymphoma \\
\hline Reactive Lymph Nodes \\
\hline Granulomatous Disease \\
\hline Sarcoid \\
\hline Histoplasmosis \\
\hline Tuberculosis \\
\hline Neurogenic Tumors \\
\hline Duplication Cysts \\
\hline Mediastinal Abscess/Mediastinitis \\
\hline
\end{tabular}

Correspondence: Thomas J. Savides, M.D. · UCSD Gastroenterology (8413) · 200 West Arbor Drive · San Diego, CA 92103-8413 · E-mail: tsavides@ucsd.edu Bibliography: Endoscopy 2006; 38 (S1): S73-S76 @ Georg Thieme Verlag KG Stuttgart · New York · ISSN 0013-726X · DOI 10.1055/s-2006-946660 ent in a lymph node, the chance of malignancy is $80-100 \%[2,3]$. However, since all 4 features are only seen in $25 \%$ of malignant lymph nodes, tissue sampling is important to obtain diagnostic material [3].

\section{EUS/FNA and trucut biopsy of posterior mediastinal lymph nodes}

Trans-esophageal EUS/FNA is performed using a linear array echoendoscope and usually a 22-gauge aspiration needle. If there is more than one lesion, the one which is most likely to be malignant (i.e. rounder, larger, more demarcated) is chosen as the target [4]. In the United States, the slides are often prepared and evaluated immediately to determine adequacy. If preliminary evaluation suggests lymphoma, then additional passes may be obtained for flow cytometry, and if suspicious for infection, then additional passes made for microbiologic studies. Final diagnosis is provided after the pathologist has evaluated all processed specimen slides, cellblock, and any additional material.

EUS-guided Trucut biopsy using a 19-gauge needle device has also been reported $[5,6]$. The potential advantage of core biopsies is preservation of tissue architecture. Some pathologists are more familiar with and prefer tissue sections. Some suggest histologic core with touch preparations, immediate cytologic evaluation, and then EUS/FNA for additional material [6]. However, touch preps may not demonstrate representative cells and crush artifact may be introduced to the core. Another disadvantage of core biopsy is technical difficulties with the current generation Trucut needle which limits its utility if tightly angulated. The Trucut needle may be useful in selected cases of mediastinal lymph nodes or masses for suspected smooth muscle tumors, sarcomas, and lymphomas, or when FNA cytology is non-diagnostic [7].

The overall accuracy rate for diagnosing posterior mediastinal malignancy with trans-esophageal EUS/FNA is approximately $93 \%$ [4]. The diagnostic accuracy of malignant posterior mediastinal lymph nodes increases with EUS/FNA cytology compared to EUS appearance alone. The risks of trans-esophageal EUS/FNA of mediastinal lymph nodes appears to be very small, but potentially includes mediastinitis, bleeding, stridor, or perforation [812].

\section{Differential diagnosis of enlarged posterior mediastinal lymph nodes}

Enlarged mediastinal lymph nodes are usually defined by CT size $\geq 1 \mathrm{~cm}$ diameter. In the setting of a peripheral lung mass and mediastinal lymph nodes, the main concern is primary lung cancer with metastatic disease. The finding of unexplained numerous posterior mediastinal and hilar lymph nodes introduces a broader differential diagnosis: benign (sarcoid, histoplasmosis, tuberculosis, reactive) or malignant (especially lymphoma).

\section{Malignant posterior mediastinal lymph nodes}

The rate of a malignant diagnosis in EUS/FNA of posterior mediastinal nodes in patients without a known diagnosis of cancer var- 
ies depending on prior bronchoscopic evaluation and local referral patterns, but is approximately $50 \%[8,13]$. The overall sensitivity, specificity, and accuracy for diagnosing malignancy in posterior mediastinal lymph nodes with EUS/FNA is greater than $90 \%[4,8,10]$.

\section{Metastatic disease to the posterior mediastinum}

A variety of tumors metastasize to the posterior mediastinum, appearing as either a lymph node or mass. The most common metastatic lesion is primary lung cancer, of which $80 \%$ is nonsmall cell lung cancer (NSCLC) and the remaining $20 \%$ small cell carcinoma. Metastases from breast, colon, kidney, testis, larynx, pancreas, liver, and esophagus have been diagnosed by transesophageal EUS/FNA [14,11,15 - 17].

\section{Lymphoma}

Material from EUS/FNA can be evaluated by cytology, immunohistochemistry, and flow cytometry, allowing diagnosis and workup of lymphoma in posterior mediastinal lymph nodes [18-21]. The sensitivity of diagnosing lymphoma can be increased (from $44 \%$ to $86 \%$ ) by adding flow cytometry and immunocytochemistry [18]. Lymphoma can be rarely be associated with granulomas on lymph node FNA cytology, an important diagnostic caveat. Since additional studies require more material, a lymphoma diagnosis may necessitate additional needle passes. For some lymphomas, such as low grade follicular lesions, Trucut biopsies may provide helpful architectural details [5]. A few series have found that lymphoma was diagnosed with Trucut biopsies when cytology was non-diagnostic, although it is not clear whether immediate cytologic evaluation, flow cytometry, and/ or immunostains were done in these cases $[18,22]$.

\section{Benign posterior mediastinal lymph nodes}

\section{Reactive lymph nodes}

Reactive lymph nodes are a usually the result of previous pulmonary infections or inhaled irritants. They have benign EUS features, and often have a draping or triangular appearance. Cytologically, they show a polymorphous population of lymphoid elements, sometimes with anthrocotic pigment in macrophages.

\section{Granulomatous lymph nodes}

Granulomatous disease is diagnosed in EUS/FNA samples by its characteristic appearance of collections of palisaded histiocytes in a background of lymphocytes. The differential diagnosis includes sarcoid, histoplasmosis, tuberculosis, and coccidiomycosis. Necrosis or caseation in a lymph node can be seen with different etiologies and is not specific for tuberculosis. EUS/FNA material should be sent for fungal and mycobacterial stains and when infectious etiology is suspected.

\section{Sarcoid}

Sarcoid is a multisystem granulomatous disease of unknown etiology which commonly involves mediastinal lymph nodes. The EUS appearance of mediastinal sarcoid lymphadenopathy is generally several enlarged benign appearing lymph nodes. The final diagnosis requires clinical criteria and exclusion of other causes of granulomatous disease. There are no pathognomic laboratory or cytology findings. Elevated serum angiotensin converting en- zyme levels support the diagnosis of sarcoid as does typically non necrotic granulomatous inflammation in mediastinal lymph nodes. EUS/FNA can obtain granulomatous material with high accuracy [23-25]. One retrospective study found the sensitivity and specificity of EUS/FNA for diagnosing granulomas in suspected sarcoid to be $89 \%$ and $96 \%$, respectively [26]. Another EUS/FNA study demonstrated noncaseating granulomas in 41 of 50 patients $(82 \%)$ with a final clinical diagnosis of sarcoidosis [25].

\section{Histoplasmosis}

Histoplasma capsulatum infection is found worldwide. Within the United States, infection is most common in the midwestern states along the Ohio and Mississippi Rivers. The diagnosis is made by histopathology, serologic testing, and/or antigen testing. Histoplasmosis is usually suspected in patients from endemic areas with pulmonary symptoms or because of incidentally found posterior mediastinal adenopathy. The EUS appearance is several enlarged, benign appearing lymph nodes which may be matted together and calcified. EUS/FNA can identify granulomas in patients with suspected histoplasmosis $[27,28]$.

\section{Tuberculosis}

Mycobacterium tuberculosis can cause enlarged mediastinal lymph nodes or a nodal mass. EUS/FNA can obtain material for M. tuberculosis culture $[13,24,29-31]$. The addition of polymerase chain reaction testing for mycobacterium tuberculosis in EUS/FNA obtained samples may increase the diagnostic yield compared to cytology and culture in patients suspected to have tuberculosis.

\section{Mediastinal masses}

The EUS distinction between a posterior mediastinal mass and lymph node can be difficult, because some lymph nodes are very large while some masses are very small. Additionally, numerous lymph nodes matted together can form a "mass". Usually a mass is larger than an enlarged lymph node (i.e. several centimeters diameter), but there is no standardized terminology.

The differential diagnosis of a posterior mediastinal mass includes primary lung cancer extending into the posterior mediastinum, metastatic cancer (either primary lung or non-thoracic cancer), neurogenic tumor, cyst, and infection. Trans-esophageal EUS/FNA can easily sample large posterior mediastinal masses.

\section{Malignant posterior mediastinal masses}

Just as with mediastinal lymph nodes, approximately $50 \%$ of mediastinal masses assessed by EUS/FNA are malignant $[14,15,32,33]$. Primary lung cancer masses abutting the esophagus are easily and safely biopsied with trans-esophageal EUS/ FNA [34]. Mass-forming nodal metastases from lung, breast, colon, kidney, testicle, cervix, larynx, and esophagus have been diagnosed with trans-esophageal EUS/FNA $[14,12,15,34]$. EUS with trucut biopsy was able to diagnose a posterior mediastinal sarcoma which could not be diagnosed with EUS/FNA cytology [5]. 
Neurogenic tumors

Primary neoplasms of the posterior mediastinum are rare. Approximately $75 \%$ are neurogenic, arising from peripheral nerves (schwannoma, neurilemoma, neurofibroma, nerve-sheath tumors), sympathetic ganglia (ganglioneuroma, ganglioneuroblastoma, neuroblastoma), or parasympathetic ganglia (paraganglionoma). These are usually benign tumors, but approximately $10-$ $20 \%$ may be malignant. Use of EUS/FNA cytology and Trucut biopsy have been reported to diagnosis mediastinal schwannomas $[35,36]$.

\section{Benign posterior mediastinal masses}

Benign mediastinal "masses" which can be diagnosed with EUS/ FNA include cysts, histoplasmosis, sarcoidosis, leiomyoma, tuberculomas, and teratomas [14].

\section{Mediastinal cysts}

Congenital foregut cysts are the most common benign mediastinal cysts, accounting for $10-15 \%$ of mediastinal masses. They probably arise as a result of aberrant development of the primitive foregut and are categorized on the basis of the embryonic origin into bronchogenic or neuroenteric (esophageal duplication cysts and neuroenteric cysts). Esophageal duplication cysts are adherent to the esophagus, while those away from the esophageal wall are suggestive of bronchogenic cysts. The pathologic evaluation of duplication cysts reveals them to be typically lined by columnar epithelia. Foregut cysts may show ciliated epithelium or detached cilia in the aspirated fluid.

Most patients with posterior mediastinal cysts are asymptomatic, and the cysts are discovered incidentally during other imaging studies. When symptoms occur, they can include chest pain, cough, dyspnea, and dysphagia. CT scan findings include welldefined, homogenous lesions ranging in size form $2-10 \mathrm{~cm}$. They are non-enhancing with intravenous contrast. They can sometimes be mistaken for a mass based on CT findings. Surgical resection may be indicated in symptomatic patients. Because the malignant potential is considered to be extremely rare, incidentally found lesions can usually be followed clinically.

The EUS appearance of a mediastinal cyst is usually a round or tubular anechoic structure with acoustic enhancement [37-40]. It is often difficult to determine if the cyst is bronchogenic or esophageal in origin by EUS, and therefore the general term duplication cyst is often used to describe the lesion. Some cysts appear to be a mass lesion because of a more hypoechoic (rather than anechoic) echotexture and minimal acoustic enhancement. These mass-like cysts usually consist of a thick gelatinous cyst material [40-43].

Cysts have been aspirated with EUS/FNA, but usually only when the EUS is not highly compatible with a cyst, and instead appears to be a possible mass $[37,40,42-45]$. There have been reports of patients developing mediastinitis and/or cyst infection after undergoing EUS/FNA, including several with the use of trucut needle biopsy [41,36,42,45-47]. These patients required treatment with antibiotics, surgery, and/or endoscopic cyst drainage. Of note, most of these reported no antibiotic prophylaxis. A more recent series which used antibiotics around of the time of the FNA reported no complications [43].

Since most posterior mediastinal cysts are benign and mediastinitis is a recognized complication, obvious posterior mediastinal duplication cysts should not be aspirated with EUS/FNA. If it is unclear whether the lesion is a cyst or a malignancy, then the safest next diagnostic test might be thoracic MRI or CT to confirm there is a cyst [42]. If EUS/FNA is performed on a lesion which turns out to be a cyst rather than a solid mass, then the cyst should be completely drained if possible, and prophylactic antibiotics should be administered, such as intravenous antibiotics during the procedure and oral antibiotics for the next $3-5$ days after to minimize any risk of mediastinitis [43]. EUS-guided truecut needle biopsies should be avoided in suspected posterior mediastinal cysts because of the risk of mediastinitis.

\section{Mediastinal abscess/mediastinitis}

EUS/FNA may have a role in the management of acute mediastinitis and abscess occurring after thoracic surgery or esophageal perforation. Fritscher-Ravens reported a series of 18 critically-ill patients with clinical mediastinitis (mostly after thoracic surgery) who underwent EUS/FNA [31]. The EUS appearance of the abscesses were $2-4 \mathrm{~cm}$, inhomogeneous, well-demarcated hypoechoic areas. Some lesions had hyperechoic $2-3 \mathrm{~mm}$ spots with shadowing, which were felt to represent air. EUS/FNA revealed purulent material and bacterial organisms on microbiology culture. There were no apparent complications from performing EUS/FNA into the mediastinal abscesses. EUS/FNA has also been reported to diagnose candida mediastinitis [48]. There have been reports of mediastinal abscess/mediastinitis managed with EUS-guided drainage and/or placement of trans-esophageal pigtail stents $[49,50]$.

\section{Conclusion}

EUS is a very safe and effective means of visualizing and characterizing posterior mediastinal lesions. EUS/FNA allows accurate and safe biopsy of posterior mediastinal lesions. Because of the high rate of reported infectious complications, EUS/FNA of obvious mediastinal cysts should be avoided.

\section{References}

${ }^{1}$ Wiersema MJ, Hassig WM, Hawes RH, Wonn MJ. Mediastinal lymph node detection with endosonography. Gastrointest Endosc 1993; 39 (6): $788-793$

2 Catalano MF, Sivak MVJr, Rice T, Gragg LA, Van Dam J. Endosonographic features predictive of lymph node metastasis. Gastrointest Endosc 1994; 40 (4): $442-446$

${ }^{3}$ Bhutani MS, Hawes RH, Hoffman BJ. A comparison of the accuracy of echo features during endoscopic ultrasound (EUS) and EUS-guided fine-needle aspiration for diagnosis of malignant lymph node invasion. Gastrointest Endosc 1997; 45 (6): $474-479$

${ }^{4}$ Wallace MB, Fritscher-Ravens A, Savides TJ. Endoscopic ultrasound for the staging of non-small-cell lung cancer. Endoscopy 2003; 35 (7): 606-610 
${ }^{5}$ Levy MJ, Jondal ML, Clain J, Wiersema MJ. Preliminary experience with an EUS-guided trucut biopsy needle compared with EUS-guided FNA. Gastrointest Endosc 2003; 57 (1): 101 - 106

${ }^{6}$ Gines A, Wiersema MJ, Clain JE, Pochron NL, Rajan E, Levy MJ. Prospective study of a Trucut needle for performing EUS-guided biopsy with EUS-guided FNA rescue. Gastrointest Endosc 2005; 62 (4): 597-601

${ }^{7}$ Levy MJ, Wiersema MJ. EUS-guided Trucut biopsy. Gastrointest Endosc 2005; 62 (3): 417 - 426

${ }^{8}$ Savides TJ, Perricone A. Impact of EUS-guided FNA of enlarged mediastinal lymph nodes on subsequent thoracic surgery rates. Gastrointest Endosc 2004; 60 (3): 340-346

${ }^{9}$ Fritscher-Ravens A, Soehendra N, Schirrow L et al. Role of transesophageal endosonography-guided fine-needle aspiration in the diagnosis of lung cancer. Chest 2000; 117 (2): 339-345

${ }^{10}$ Eloubeidi MA, Cerfolio RJ, Chen VK, Desmond R, Syed S, Ojha B. Endoscopic ultrasound-guided fine needle aspiration of mediastinal lymph node in patients with suspected lung cancer after positron emission tomography and computed tomography scans. Ann Thorac Surg 2005; 79 (1): $263-268$

11 Will U, Meyer F, Bosseckert H. Successful endoscopic management of iatrogenic mediastinal infection and subsequent esophagomediastinal fistula, following endosonographically guided fine-needle aspiration biopsy. Endoscopy 2005; 37 (1): 88 -90

12 Pai KR, Page RD. Mediastinitis after EUS-guided FNA biopsy of a posterior mediastinal metastatic teratoma. Gastrointest Endosc 2005; 62 (6): $980-981$

${ }^{13}$ Fritscher-Ravens A, Sriram PV, Bobrowski C et al. Mediastinal lymphadenopathy in patients with or without previous malignancy: EUSFNA-based differential cytodiagnosis in 153 patients. Am J Gastroenterol 2000; 95 (9): 2278 - 2284

${ }^{14}$ Devereaux BM, LeBlanc JK, Yousif E et al. Clinical utility of EUS-guided fine-needle aspiration of mediastinal masses in the absence of known pulmonary malignancy. Gastrointest Endosc 2002; 56 (3): $397-401$

15 DeWitt J, Ghorai S, Kahi C et al. EUS-FNA of recurrent postoperative extraluminal and metastatic malignancy. Gastrointest Endosc 2003; 58 (4): $542-548$

${ }^{16}$ Kramer H, Koeter GH, Sleijfer DT, van Putten JW, Groen HJ. Endoscopic ultrasound-guided fine-needle aspiration in patients with mediastinal abnormalities and previous extrathoracic malignancy. Eur J Cancer 2004; 40 (4): 559 - 562

${ }^{17}$ Hahn M, Faigel DO. Frequency of mediastinal lymph node metastases in patients undergoing EUS evaluation of pancreaticobiliary masses. Gastrointest Endosc 2001; 54 (3): 331 - 335

18 Ribeiro A, Vazquez-Sequeiros E, Wiersema LM, Wang KK, Clain JE, Wiersema MJ. EUS-guided fine-needle aspiration combined with flow cytometry and immunocytochemistry in the diagnosis of lymphoma. Gastrointest Endosc 2001; 53 (4): 485-491

${ }^{19}$ Hoda RS, Picklesimer L, Green KM, Self S. Fine-needle aspiration of a primary mediastinal large B-cell lymphoma: a case report with cytologic, histologic, and flow cytometric considerations. Diagn Cytopathol 2005; 32 (6): 370-373

${ }^{20}$ Mehra M, Tamhane A, Eloubeidi MA. EUS-guided FNA combined with flow cytometry in the diagnoses of suspected or recurrent intrathoracic or retroperitoneal lymphoma. Gastrointest Endosc 2005; 62(4): $508-513$

${ }^{21}$ Noh KW, Wallace MB. Can EUS-guided FNA with flow cytometry be used to diagnose lymphoma? Gastrointest Endosc 2005; 62 (4): $514-516$

22 Storch I, Jorda M, Ribeiro A. EUS-guided biopsy in the diagnosis of pulmonary lymphoma in a patient with an esophagopulmonary fistula. Gastrointest Endosc 2005; 61 (7): 904-906

${ }^{23}$ Mishra G, Sahai AV, Penman ID et al. Endoscopic ultrasonography with fine-needle aspiration: an accurate and simple diagnostic modality for sarcoidosis. Endoscopy 1999; 31 (7): 377-382

${ }^{24}$ Fritscher-Ravens A, Sriram PV, Topalidis T et al. Diagnosing sarcoidosis using endosonography-guided fine-needle aspiration. Chest 2000; 118 (4): $928-935$

${ }^{25}$ Annema JT, Veselic M, Rabe KF. Endoscopic ultrasound-guided fineneedle aspiration for the diagnosis of sarcoidosis. Eur Respir J 2005; 25 (3): 405-409

${ }^{26}$ Wildi SM, Judson MA, Fraig M et al. Is endosonography guided fine needle aspiration (EUS-FNA) for sarcoidosis as good as we think? Thorax 2004; 59 (9): 794-799
${ }^{27}$ Wiersema MJ, Chak A, Wiersema LM. Mediastinal histoplasmosis: evaluation with endosonography and endoscopic fine-needle aspiration biopsy. Gastrointest Endosc 1994; 40 (1): 78 - 81

${ }^{28}$ Savides TJ, Gress FG, Wheat LJ, Ikenberry S, Hawes RH. Dysphagia due to mediastinal granulomas: diagnosis with endoscopic ultrasonography. Gastroenterology 1995; 109 (2): 366 - 373

${ }^{29}$ Hainaut $\mathrm{P}$, Monthe A, Lesage V, Weynand B. Tuberculous mediastinal lymphadenopathy. Acta Clin Belg 1998; 53 (2): 114-116

30 Kramer H, Nieuwenhuis JA, Groen HJ, Wempe JB. Pulmonary tuberculosis diagnosed by esophageal endoscopic ultrasound with fine-needle aspiration. Int J Tuberc Lung Dis 2004; 8 (2): 272 - 273

${ }^{31}$ Fritscher-Ravens A, Schirrow L, Pothmann W, Knofel WT, Swain P, Soehendra N. Critical care transesophageal endosonography and guided fine-needle aspiration for diagnosis and management of posterior mediastinitis. Crit Care Med 2003; 31 (1): 126-132

32 Catalano MF, Rosenblatt ML, Chak A, Sivak MVJr, Scheiman J, Gress F. Endoscopic ultrasound-guided fine needle aspiration in the diagnosis of mediastinal masses of unknown origin. Am J Gastroenterol 2002; 97 (10): 2559-2565

33 Panelli F, Erickson RA, Prasad VM. Evaluation of mediastinal masses by endoscopic ultrasound and endoscopic ultrasound-guided fine needle aspiration. Am J Gastroenterol 2001; 96 (2): 401 - 408

${ }^{34}$ Varadarajulu S, Hoffman BJ, Hawes RH, Eloubeidi MA. EUS-guided FNA of lung masses adjacent to or abutting the esophagus after unrevealing CT-guided biopsy or bronchoscopy. Gastrointest Endosc 2004; 60 (2): $293-297$

${ }^{35}$ McGrath KM, Ballo MS, Jowell PS. Schwannoma of the mediastinum diagnosed by EUS-guided fine needle aspiration. Gastrointest Endosc 2001; 53 (3): $362-365$

${ }^{36}$ Varadarajulu S, Fraig M, Schmulewitz $\mathrm{N}$ et al. Comparison of EUSguided 19-gauge Trucut needle biopsy with EUS-guided fine-needle aspiration. Endoscopy 2004; 36 (5): 397 - 401

37 Van DJ, Rice TW, Sivak MVJr. Endoscopic ultrasonography and endoscopically guided needle aspiration for the diagnosis of upper gastrointestinal tract foregut cysts. Am J Gastroenterol 1992; 87 (6): 762 765

38 Geller A, Wang KK, DiMagno EP. Diagnosis of foregut duplication cysts by endoscopic ultrasonography. Gastroenterology 1995; 109 (3): $838-842$

${ }^{39}$ Bhutani MS, Hoffman BJ, Reed C. Endosonographic diagnosis of an esophageal duplication cyst. Endoscopy 1996; 28 (4): 396 - 397

${ }^{40}$ Faigel DO, Burke A, Ginsberg GG, Stotland BR, Kadish SL, Kochman ML. The role of endoscopic ultrasound in the evaluation and management of foregut duplications. Gastrointest Endosc 1997; 45 (1): 99-103

${ }^{41}$ Wildi SM, Hoda RS, Fickling W et al. Diagnosis of benign cysts of the mediastinum: the role and risks of EUS and FNA. Gastrointest Endosc 2003; 58 (3): $362-368$

42 Westerterp M, van den Berg JG, van Lanschot JJ, Fockens P. Intramural bronchogenic cysts mimicking solid tumors. Endoscopy 2004; 36 (12): $1119-1122$

43 Fazel A, Moezardalan K, Varadarajulu S, Draganov P, Eloubeidi MA. The utility and the safety of EUS-guided FNA in the evaluation of duplication cysts. Gastrointest Endosc 2005; 62 (4): 575-580

${ }^{44}$ Eloubeidi MA, Cohn M, Cerfolio RJ et al. Endoscopic ultrasound-guided fine-needle aspiration in the diagnosis of foregut duplication cysts: the value of demonstrating detached ciliary tufts in cyst fluid. Cancer 2004; 102 (4): $253-258$

${ }^{45}$ Ryan AG, Zamvar V, Roberts SA. Iatrogenic candidal infection of a mediastinal foregut cyst following endoscopic ultrasound-guided fineneedle aspiration. Endoscopy 2002; 34 (10): 838-839

${ }^{46}$ Wiersema MJ, Vilmann P, Giovannini M, Chang KJ, Wiersema LM. Endosonography-guided fine-needle aspiration biopsy: diagnostic accuracy and complication assessment. Gastroenterology 1997; 112 (4): $1087-1095$

${ }^{47}$ Annema JT, Veselic M, Versteegh MI, Rabe KF. Mediastinitis caused by EUS-FNA of a bronchogenic cyst. Endoscopy 2003; 35 (9): 791 - 793

48 Prasad VM, Erickson R, Contreras ED, Panelli F. Spontaneous candida mediastinitis diagnosed by endoscopic ultrasound-guided, fine-needle aspiration. Am J Gastroenterol 2000; 95 (4): 1072 - 1075

${ }^{49}$ Kahaleh M, Yoshida C, Kane L, Yeaton P. EUS drainage of a mediastina abscess. Gastrointest Endosc 2004; 60 (1): 158 - 160

${ }^{50}$ Wehrmann T, Stergiou N, Vogel B, Riphaus A, Kockerling F, Frenz MB. Endoscopic debridement of paraesophageal, mediastinal abscesses: a prospective case series. Gastrointest Endosc 2005; 62 (3): 344-349 